\title{
A POSIÇÃO ORIGINAL DE JOHN RAWLS COMO MODELO PARA A SOCIEDADE DOS POVOS
}

\author{
$*$ \\ Ubiratan Trindade \\ Universidade do Vale do Rio dos Sinos - UNISINOS - Brasil
}

\section{Resumo}

Este trabalho tem a pretensão de refletir sobre se seria possível realizar a utopia proposta por John Rawls em sua obra O Direito dos Povos (2001). É tarefa da filosofia política, como o próprio Rawls admitia cumprir um papel de ser realisticamente utópica, com a pretensão de expandir os limites da possibilidade da política prática. Sua esperança era que a humanidade tivesse como base a crença de que a natureza do mundo social viesse permitir existir sociedades democráticas constitucionais, razoavelmente justas e que, as mesmas fizessem parte da Sociedade dos Povos. Neste mundo social, a paz e a justiça seriam obtidas entre povos liberais, nacional e internacionalmente. Se em Uma Teoria da Justiça (1971) e no Liberalismo Político (1993) Rawls reflete a possibilidade da existência de uma sociedade liberal, justa e igualitária, em $O$ Direito dos Povos, sua reflexão coloca como seria possível uma sociedade mundial de povos liberais. O que motivou Rawls escrever esta obra foi os "grandes males" da humanidade, tais como a guerra injusta, a opressão, a perseguição religiosa, a fome, a pobreza, a imigração, os refugiados e a liberdade de consciência. O artigo parte da ideia da posição original como um modelo de representação para a construção de sociedades liberais. Servindo-se da alegoria da posição original, que segue alguns passos, como por exemplo, o véu da ignorância com o qual iremos demonstrar uma possível espécie de segunda posição original. Se, no primeiro modelo, ela serve para construir uma sociedade justa no interior de um Estado, no segundo modelo, poderia servir para a construção de uma Sociedade dos Povos? Esta é a resposta que vamos encaminhar a partir dessa investigação.

Palavras chave: Direito, Justiça, Posição Original, Rawls, Sociedade dos povos.

\section{Situando o problema}

Com alguns avanços e recuos podemos dizer, sem dúvidas, que vivemos o apogeu da civilização globalizada. No debate atual, diversas são as maneiras de justificar o interesse pela dimensão política da globalização. Para alguns, a globalização é inevitável dado o alto grau da complexidade tecnológica envolvida nas atividades humanas para a produção de bens e serviços. Outros ressaltam o ritmo acelerado das relações e das dependências entre os diversos países, no que se refere aos diversos problemas políticos, econômicos, sociais e ambientais. Cada vez mais, percebe-se que as adversidades daí decorrentes, não podem ser resolvidas apenas no âmbito do Estado nacional. Uma reflexão mais profunda desse problema requer por parte dos thinkers atuais o entrelaçamento entre Estados nacionais e um novo regramento 
jurídico Internacional. Consoante Jürgen Habermas em sua obra The Postnational Constellation: Political Essays (1998), não se concebe mais nos dias atuais um Estado isolado dos demais. Os Estados nacionais estariam sofrendo uma sobrecarga de demandas que ficariam acima de suas possibilidades de solucioná-las. Esta é também, por exemplo, uma das preocupações de Zygmunt Bauman quando fala que "o Estado-nação perdeu sua força que agora se evapora no espaço global” (2007, p. 31). Para Bauman, as grandes corporações e o poder econômico não se limitam mais às fronteiras geográficas. $\mathrm{O}$ mais preocupante é que essas instituições ocupam o lugar do Estado social deixando a política em segundo plano. Neste sentido, é notório dizer que a ordem jurídico-estatal internacional baseada na soberania dos Estados nacionais já não é mais suficiente para garantir uma ordem justa.

Outro filósofo preocupado com o Direito Internacional e a globalização é Otfried Höffe. Para ele, existe a necessidade de uma ação global com o objetivo de dar conta de várias demandas da sociedade e dos povos. Não é apenas a Economia que requerer atenção. A preocupação deve estender-se para o campo da Política, Ciência, Educação e Cultura, ao crime organizado e especialmente às ameaças ao meio ambiente. Para Höffe, os instrumentos da Diplomacia Clássica e o Direito Internacional, as alianças interestatais e as organizações internacionais existentes, entre elas as Nações Unidas, têm-se revelado deficientes. Assim, uma nova ordem política ou jurídico-estatal deve surgir para dar garantias e condições de desenvolvimento às democracias liberais. Na obra A Democracia no Mundo de Hoje (2005), Höffe reflete sobre uma nova ordem jurídica e estatal mundial. Recusa aceitar um Estado Mundial, no entanto, propõe uma República Mundial como solução para esse dilema. Consoante sua base normativa sustentada na autodeterminação dos indivíduos, a moral e a justiça são dotadas, em princípio, em um caráter universalista. A meta é alcançar um consenso jurídico que esteja a serviço da comunidade global, sem ceder aos egoísmos extremados e vorazes do mercado. A inovação deve trazer em seu conteúdo uma ordem jurídica e estatal global, dotada e caráter democrático. A meta seria atingir uma República Mundial democrática ou uma res publica global.

Resta à filosofia política refletir sobre a possibilidade de tal empreendimento. Como veremos em seguida na Doutrina do Direito de Kant, teoricamente é possível definir uma ordem jurídica normativa sem uma ordem estatal. Ocorre que, além dos direitos e deveres morais, a moral política e a justiça exigem uma institucionalização jurídica como o Direito positivo, pois, somente desta forma os direitos e deveres podem ser garantidos efetivamente através dos instrumentos coercitivos do monopólio do poder do Estado. Assim, uma ordem política justa, dependeria da existência de um modelo estatal ou algo semelhante a um Estado. 
É por essa razão que se levanta a questão tanto filosófica quanto política, sobre se seria possível e no caso afirmativo, qual seria o tipo de ordem social apropriada para uma provável justiça internacional, transnacional e global, ou melhor, uma República Mundial. O conceito de res publica remonta à Antiguidade Clássica e foi definido por Cícero como uma reunião que tem seu fundamento no consentimento jurídico e na utilidade comum (1995, I, 25, 39). Ainda que falemos, portanto, de um Estado Mundial ou República Mundial, devemos refletir a partir de um consenso jurídico e no conjunto de pessoas associadas em torno desse consenso.

Dos filósofos ocidentais mais importantes que elevaram a uma categoria superior o tema sobre a paz entre os povos, dois devem ser destacados: o primeiro, Santo Agostinho nos primórdios da teologia cristã. O segundo, Kant, no auge do Iluminismo. "Por um lado, Kant vinculou as teorias do Direito e do Estado desde a Antiguidade com o cosmopolitismo profundamente apolítico dos estoicos e, por outro lado, bem como o Direito Internacional da Idade Moderna com a ideia de uma paz perpétua" (HÖFFE, 2005, p. 301). Uma paz perpétua que seria realizada por meio do Direito e em conformidade com seu conceito moral. Para Höffe, o principal texto de Kant sobre essa temática se refere a um contexto sobre a Paz da Basiléia vivido entre França e a Prússia no final do século XVIII. O ensaio À paz perpétua de 1795 é puramente filosófico e isento de motivos religiosos ou políticos. Contém, no entanto, os princípios de uma filosofia integral do Direito e do Estado, e apresenta os princípios destinados a transformá-la em política real. Em um Anúncio de um tratado para uma paz perpétua na filosofia de 1787, Kant mostra que a paz perpétua é um objetivo geral por ele perseguido, não deixando de ser uma inovação para a época, em se tratando da teoria da paz ocidental vista do ponto filosófico. Kant entendia a paz, como um motivo fundamental ligado não apenas ao pensamento político, mas, ao pensamento e à reflexão como um todo. Necessário destacar que, Jeremy Bentham ${ }^{1}$, foi o único dos filósofos mais importantes do Iluminismo que, além de Kant, elaborou uma teoria do direito internacional e da paz universal.

\section{Relações internacionais entre os povos}

Partindo do exposto acima, gostaríamos de sugerir que John Rawls tem muito a contribuir para o debate sobre as relações internacionais entre os povos. A questão dos

\footnotetext{
${ }^{1}$ Seu texto A Plan for na Universal and Perpetual Peace (1786) só foi publicado em 1843, tendo recebido o título de Principles of International Law. Para maiores detalhes ver: HÖFFE, Otfried. A Democracia no mundo de Hoje. São Paulo: Martins Fontes, 2005, p. 309.
} 
direitos humanos não mereceu grande destaque nas principais obras de Rawls. Como ele mesmo admite este importante tema foi tratado apenas superficialmente na seção 58 de A Theory of Justice ${ }^{2}$. Com base nestas considerações preliminares vamos analisar se o artifício de representação da posição original, proposto por John Rawls, em A Theory of Justice de (1971), pode nos trazer alguma contribuição para este debate. Assim, este trabalho de investigação tem a pretensão de refletir sobre as possibilidades da realização de uma Sociedade dos Povos como proposto por John Rawls em sua obra O Direito dos Povos (2001). Segundo ele, é tarefa da filosofia política, cumprir um papel de ser realisticamente utópica, tendo a pretensão de expandir os limites da possibilidade da política prática. Sua esperança é que a humanidade, em especial, as sociedades liberais tenham como base a crença de que a natureza do mundo social venha contribuir e permitir a existência de sociedades democráticas constitucionais razoavelmente justas.

Importante termos em mente que uma teoria da justiça filosófica é normativa. Ela argumenta a favor de como as coisas deveriam ser, em vez de indicar como as coisas, de fato, se colocam. Uma filosofia política não tem a pretensão de demonstrar o que as pessoas pensam sobre o que é a justiça. Ela, ao invés disto, diz o que as pessoas deveriam pensar sobre a justiça. Para muitos leitores isto parecerá, a princípio, uma teoria desengajada dos problemas concretos das sociedades atuais e das injustiças sofridas por pessoas reais. Seria como um pensamento utópico em que se contempla a vida sentado numa poltrona, sem perceber a necessidade da praticidade da ação. No entanto, esta forte dicotomia do que é a coisa e o que deveria ser a coisa é profundamente enganador e, o primeiro passo, para entender o poder da teoria da justiça de Rawls é tentar evitá-la. Primeiro, uma teoria da justiça, enquanto sendo normativa, está ancorada nas realidades da natureza humana e nas possibilidades da sociedade humana. E, se deveríamos ser anjos, então, uma teoria da justiça seria de interesse apenas para os anjos. Segundo, qualquer teoria da justiça plausível deve desafiar e aumentar nosso senso moral e nossa ação política. A teoria da justiça como equidade de John Rawls desafia-nos a ir além de nós mesmos e ir em direção àquilo que não somos, mas queremos nos tornar. Isto requer um ato de imaginação: uma projeção de nós mesmos em direção a um futuro possível e imaginado (VOICE, 2011, p. p.7-8).

Neste mundo social, a paz e a justiça seriam obtidas entre povos liberais, nacional e internacionalmente. Se em Uma Teoria da Justiça (1971) e posteriormente no Liberalismo Político (1993), Rawls reflete a possibilidade da existência de uma sociedade liberal, justa e

\footnotetext{
${ }^{2}$ RAWLS, John. Collected Papers, ed. Samuel Freeman. Cambridge. MA: Harvard University Press, 1999, p. 529.
} 
igualitária, em O Direito dos Povos (2001), sua reflexão parte de como seria possível uma sociedade mundial de povos liberais. É baseado nas ideias que Rawls desenvolveu em conferências e artigos escritos no inicio dos anos de 1990. "Enquanto os trabalhos anteriores de Rawls eram dedicados ao problema da justiça dentro das sociedades democráticas, The Law of Peoples examina os problemas da justiça internacional" (VOICE, 2011, p. p. 4-5). O que motivou Rawls a escrever esta obra, foi os "grandes males" da humanidade, tais como a guerra injusta, a opressão, a perseguição religiosa, a fome, a pobreza, a imigração, os refugiados e a liberdade de consciência. Para aqueles que refletem o mundo de hoje, os problemas continuam sendo os mesmos e até mesmo, podemos dizer, agravaram-se.

O debate filosófico sobre a justiça global deve considerar se seria possível criar princípios de justiça com dimensão global, como uma espécie de adaptação dos princípios de justiça de um Estado nacional, onde pessoas racionais, livres e iguais fariam as escolhas dos princípios que desejam para si e para os demais. Abordar a questão da justiça com vistas a organizar uma sociedade justa, limitada por um Estado nacional, por si só, é uma tarefa hercúlea. Ampliar o escopo da justa a um alcance global parece-nos sem dúvidas, ser um desafio ainda maior. No debate sobre a justiça global devemos admitir que, existe por um lado, uma justiça política vigente para as relações entre os indivíduos no interior de um Estado nacional e, por outro lado, uma justiça internacional vigente primariamente para as relações entre os diversos Estados. A novidade de Rawls é justamente propor esta reflexão sobre a justiça em dois níveis. Na posição original, uma espécie de alegoria sugerida por Rawls em A Theory of Justice (1971), pessoas racionais, livres e iguais tomam suas decisões, colocadas sob o artifício chamado do véu da ignorância decidindo os princípios de justiça para a sociedade da qual querem viver. No primeiro nível, a relação se dá entre as próprias pessoas. No segundo nível, a relação é entre os Estados visando uma ordem mundial justa. Se no primeiro modelo a posição original auxilia para na construção de uma sociedade justa no interior de um Estado liberal e democrático, no segundo modelo, poderia servir para a construção de uma Sociedade dos Povos? Esta resposta, pretendemos dar ao final dessa investigação.

Para aceitar que um segundo nível da posição original seja possível, é necessário compreender melhor a ideia ou a genealogia do esquema de representação chamado de posição original. Para tanto, se faz necessária uma análise desse termo na obra $A$ Theory of Justice de 1971. Podemos afirmar que a posição original está para a teoria da justiça como equidade de John Rawls assim como a teoria do contrato social está para os contratualistas. "Minha tentativa foi de generalizar e elevar a uma ordem mais alta de abstração a teoria 
tradicional do contrato social representada por Locke, Rousseau e Kant” (RAWLS, 1971, p. viii). Justifica a posição original por ser um status quo inicial apropriado para assegurar que os consensos básicos nele estabelecidos sejam equitativos. Na posição original as pessoas deliberam sobre quais princípios seriam racionalmente aceitos, dada a situação contratual. Rawls associa a questão da justiça à teoria da escolha racional. "O conceito da posição original, do modo como utilizo, é o que apresenta, do ponto de vista filosófico, a interpretação mais adequada dessa situação de escolha inicial para os propósitos de uma teoria da justiça" (RAWLS, 1971, p. 18). O objetivo da abordagem neocontratualista de Rawls é estabelecer que, tomados em seu conjunto esses pressupostos, os mesmos garantirão parâmetros adequados para os princípios de justiça aceitáveis.

Algo incomum, admitido pelo próprio Rawls, o dispositivo da posição original impõe algumas restrições às partes. Parece razoável e geralmente aceitável que ninguém deva ser favorecido ou desfavorecido pela sorte natural ou por circunstâncias sociais no transcorrer da escolha dos princípios. O conhecimento das contingências, caso se é rico ou pobre, por exemplo, ficam excluídos para evitar que alguém seja favorecido ou desfavorecido. Todos ficam privados de qualquer tipo de informação. "Fica excluído o conhecimento dessas contingências que criam disparidade entre os homens e permitem que eles se orientem pelos seus preconceitos" (RAWLS, 1971, p. 19). Para Rawls, parece razoável supor, que as partes na posição original, obedecem a uma simetria em busca da justiça como equidade. Todas as pessoas têm os mesmos direitos no processo da escolha dos princípios. Cada uma pode apresentar propostas ou razões para sua melhor aceitação. O objetivo é a criação de princípios que dignifiquem as pessoas eticamente, pessoas que têm uma concepção de justiça e que são capazes de ter um senso de justiça.

Por meio de avanços e recuos, às vezes alterando as condições das circunstâncias em que se deve obter o acordo original, outras vezes modificando nossos juízos e conformandoos com os demais, supõe-se que se possa encontrar uma configuração da situação inicial que expresse pressupostos razoáveis e produza os princípios que combinem com nossas convicções apuradas, ajustadas e ponderadas, ou aquilo que Rawls chama de equilíbrio reflexivo. (RAWLS 1971, p.21).Cinco características são essenciais para entender o esquema de representação da posição original: (i) a posição original modela as partes como representando os cidadãos imparcialmente; (ii) ela os modela como racionais; (iii) ela os modela selecionando, dentre princípios de justiça disponíveis, aqueles que se aplicam ao sujeito adequado, que é, nesse caso, a estrutura básica; (iv) as partes são modeladas como fazendo essas seleções pelas razões adequadas e, (v) como selecionando por razões 
relacionadas com os interesses fundamentais dos cidadãos como razoáveis e racionais (RAWLS, 2004, p. p. 40-41). Este é o roteiro que Rawls nos apresenta quando da interpretação da alegoria da posição original. Uma tentativa de acomodar num único sistema, tanto os pressupostos filosóficos razoáveis impostos aos princípios, quanto os nossos juízos ponderados sobre a justiça. Os princípios se justificam porque foram aceitos consensualmente numa situação inicial de igualdade. Apesar de ser puramente hipotética, a noção intuitiva da posição original pode ser colocada em prática nas sociedades reais.

Chega-se então, ao véu da ignorância de forma natural. Para se estabelecer um processo equitativo de modo que os princípios aceitos sejam justos, requer-se um procedimento que anule o egoísmo extremo às possíveis disparidades vistas no mundo social. Para isso, é importante que as partes se situem atrás de um véu de ignorância (RAWLS, 1971, p. 136). Elas não podem saber como as várias alternativas irão afetar o seu caso particular. Supõe-se que as partes não conhecem certos tipos de fatos particulares. Não conhecem a sua sorte na distribuição dos dotes naturais, suas habilidades, sua inteligência ou força. Ninguém conhece a sua concepção do bem e as particularidades de seu plano de vida racional. Ou seja, conhecer sua posição econômica e política é prejudicial para a escolha dos princípios de justiça como equidade. O único fato particular que as partes conhecem é que sua sociedade está sujeita às circunstancias da justiça e a qualquer consequência que possa decorrer disso. As razões para Rawls recorrer ao dispositivo do véu da ignorância ultrapassa a mera simplicidade. Ele definiu a posição original para chegar a uma solução desejada. "Se for permitido um conhecimento das particularidades, o resultado será influenciado por contingências arbitrárias" (RAWLS, 1971, p. 141). Dar a cada um de acordo com o seu poder de ameaçar não é uma alternativa justa. Para que a posição original gere acordos justos, as partes devem estar situadas de forma equitativa e devem ser tratadas de forma igual como pessoas éticas.

Vimos até aqui, o primeiro estágio da posição original que se dá entre as partes, isto é, entre pessoas racionais, livres e iguais em um Estado democrático de direito. Agora, passamos a analisar a posição original em seu segundo estágio, ou seja, a proposta elaborada por John Rawls em sua obra The Law of Peoples (2001). O propósito do Direito dos Povos é seguir a diretiva adotada por Kant em À paz perpétua e sua ideia de foedus pacificum ${ }^{3}$. Significa estender a concepção política liberal de regime democrático constitucional a um segundo

\footnotetext{
3 “A paz não pode ser assegurada nem mantida sem um acordo geral entre as nações; assim, é necessária uma espécie particular de liga, que poderíamos designar como uma federação pacífica (foedus pacificum) (Kant, "Perpetual Peace", in Political Writings, Cambridge Um. Press, 1999, p. 104).
} 
nível. Uma espécie de pacto que fazem entre si os representantes de povos liberais. A proposta está conforme a ideia de Kant de que um regime constitucional precisa estabelecer um Direito dos Povos efetivo, com o objetivo de realizar plenamente a liberdade dos seus cidadãos. Rawls segue as pegadas de Kant, na medida em que propõe algo semelhante, embora com um novo método. Em The Law of Peoples (2001) Rawls nos oferece uma abordagem inovadora na medida em que ultrapassa o plano interno de organização de cada sociedade considerada particularmente, como foi demonstrado em A Theory of Justice (1971) e no Political Liberalism (1993). Agora, sua intenção, é estabelecer uma espécie de regramento para um plano superior da sociedade dos povos. "Com Direito dos Povos quero referir-me a uma concepção política particular de direito e justiça, que se aplica aos princípios e normas do Direito e da prática internacionais” (RAWLS, 2004, p. 3 ).

Rawls emprega o termo Sociedade dos Povos para designar todos os povos que seguem os ideais e os princípios do Direito dos Povos nas suas relações recíprocas. O termo Direito dos Povos deriva do tradicional ius gentium, e a expressão ius gentium intra, refere-se ao que os Direitos de todos os povos têm em comum. Rawls usa esse significado para designar os princípios políticos particulares que poderiam regulamentar as relações políticas mútuas entre os povos. Sua pretensão é generalizar a ideia liberal da justiça como equidade como já fizera em Uma teoria da justiça (1971) e posteriormente na obra Political Liberalism (1993), ampliando a mesma para a Sociedade Internacional. A questão que fica para responder, é, se haveria possibilidade real de um dia vir acontecer tal empreendimento. Garantir uma concepção política de justiça para uma sociedade democrática, vista como um sistema de cooperação justa entre cidadãos livres e iguais, que aceitariam os princípios de justiça publicamente reconhecidos no interior de um Estado, por si só, já não é tarefa fácil. Mesmo assim, transportar esse modelo para uma relação entre Estados parece para muitos, ser um pensamento utópico. Menos para Rawls, é claro.

Devemos admitir, no entanto, que sua tarefa de realizar o segundo uso da posição original numa relação entre Estados é pretenciosa e extremamente ambiciosa. A ideia da posição original é usada agora para estender uma concepção liberal ao Direito dos Povos. As partes agora são representantes racionais de povos liberais que devem especificar o Direito dos Povos, guiados por razões adequadas ${ }^{4}$. Tanto as partes como representantes e os povos

\footnotetext{
${ }^{4}$ As razões certas seriam as ideias e os valores políticos e morais de uma sociedade democrática. Já, o consenso sobreposto, requer um esforço por parte das pessoas no sentido de deixar em segundo plano suas doutrinas abrangentes e, elevar a um primeiro plano, os princípios que irão regular a sociedade. Em um artigo publicado em 1977, The Idea of Public Reason Revisited, Rawls nos oferece um bom exemplo do que seria, na prática, um consenso sobreposto. Começa por perguntar se seria possível para alguém que tem fé, endossar um regime
} 
que representam estão situadas simetricamente (igualmente) e, portanto, imparcialmente. "Além disso, os povos são modelados como racionais, já que as partes selecionam dentre os princípios disponíveis para o Direito dos Povos guiadas pelos interesses fundamentais das sociedades democráticas, onde esses interesses são expressos pelos princípios liberais de justiça para uma sociedade democrática" (RAWLS, 2004, p. 42). O véu da ignorância é ajustado para o modelo da Sociedade dos Povos. As partes não conhecem, por exemplo, o tamanho do território, o nível de desenvolvimento econômico, a população ou a força relativa do povo cujos interesses representam. Isso torna o uso da posição original no segundo nível um modelo de representação exatamente da maneira como no primeiro.

As cinco características que apareceram no primeiro nível voltam agora modelados para o caso em questão. Os representantes do povo são (i) razoável e justamente situados como livres e iguais e os povos são (ii) modelados como racionais. Seus representantes (iii) deliberam sobre o conteúdo do Direito dos Povos que tem como função governar a estrutura básica das relações entre os povos. (iv) As suas deliberações prosseguem em termos das razões certas e restritas pelo véu da ignorância. Finalmente, (v) a seleção dos princípios para o Direito dos Povos baseia-se nos interesses fundamentais de um povo, dados nesse caso, por uma concepção liberal de justiça. Os interesses dos povos liberais são especificados pela sua concepção razoável de justiça política. Lutam para proteger sua independência política, sua cultura livre e suas liberdades civis. Garantir sua segurança, o território e o bem-estar de seus cidadãos.

Importante mostrar que Rawls faz uma distinção entre povos e Estados. Para ele, povos justos estão plenamente preparados para conceder justamente o mesmo respeito e o mesmo reconhecimento adequados a outros povos, como iguais (RAWLS, 2004, p. 45). A igualdade não impede que haja desigualdades de certos tipos nas várias instituições cooperativas entre os povos. Aqui, Rawls está nos falando do princípio da diferença que aparece na primeira parte de A Theory of Justice (1971). Apesar de admitir o livre mercado e

constitucional mesmo quando as suas doutrinas abrangentes podem sofrer restrições sob esse regime. Nesse caso, o melhor seria endossar uma democracia constitucional razoável como forma de assegurar imparcialmente a liberdade dos seus seguidores compatíveis com as liberdades iguais de outros cidadãos livres e iguais. Ao afirmar um regime democrático constitucional, uma doutrina religiosa entende que esses são os limites que Deus impõe à nossa liberdade. Entende Rawls, que a liberdade de consciência e o princípio de tolerância que devem ocupar um lugar essencial em qualquer concepção democrática podem ser coerentes com a igual justiça para todos os cidadãos, em uma sociedade democrática razoável. Nos fala também, da interpretação que Abdullahi Ahmed Na-Na'im faz da Shari'a, livro sagrado (Lei Divina) dos muçulmanos que, segundo ele, deveriam seguir o período inicial de Meca quando a Shari'a sustentava a possibilidade de uma união da fé com o pensamento racional referendando uma democracia constitucional. Esse exemplo, segundo Rawls, é verdadeiro para as demais doutrinas abrangentes (filosóficas, morais e políticas). Para maiores detalhes ver: RAWLS, John. Collected Papers, ed. Samuel Freeman. Cambridge. MA: Harvard University Press, 1999, p 590-91. 
a própria meritocracia, o princípio da diferença é criado para distribuir renda de um modo equitativo. Diferenças econômicas são admitidas desde que melhorem as expectativas dos membros menos favorecidos da sociedade. O mesmo deve ocorrer na relação entre os Estados nacionais. É razoável imaginar que um povo racional esteja pronto a oferecer a outros povos, termos justos de cooperação política e social. O critério de reciprocidade aplica-se ao Direito dos Povos da mesma maneira que se aplica aos princípios de justiça para um regime constitucional.

\section{Considerações finais}

A primeira tarefa das partes na segunda posição original é especificar o Direito dos Povos, seus ideais, princípios e padrões, e como essas normas se aplicam às relações políticas entre os povos. Para consolidar uma concepção política de pessoa, Rawls encontrou uma alternativa ao que ele chama de pluralismo razoável ${ }^{5}$. Para ele, um pluralismo razoável de doutrinas abrangentes é característica básica de uma democracia constitucional com instituições livres. Neste sentido, “podemos supor que há uma diversidade ainda maior nas doutrinas abrangentes afirmadas entre os membros da Sociedade dos povos com suas várias culturas e tradições” (RAWLS, 2004, p. 52). Na sociedade dos povos, o paralelo do pluralismo razoável é a diversidade entre povos razoáveis, com suas diferentes culturas e tradições de pensamento. A intuição de Rawls é que as partes não aceitariam o utilitarismo clássico para orientar os princípios que seriam extraídos na relação entre os povos. Povos bem-ordenados levam em conta uma igualdade entre si, e essa visão, exclui qualquer forma de princípio de utilidade. O utilitarismo tende a autorizar uma redução no bem-estar e na liberdade de alguns em nome da maior felicidade de outros, geralmente, com altos privilégios na sociedade.

A percepção de Rawls é a de que pessoas representando o Direito dos Povos escolheriam princípios análogos àqueles escolhidos por pessoas racionais, livres e iguais em $A$ Theory of Justice ${ }^{6}$. Sugere então, oito princípios de justiça que, acredita, seriam escolhidos por representantes de povos livres e democráticos. (1) Os povos são livres e independentes, e a sua liberdade e independência devem ser respeitadas por outros povos; (2) Os povos devem observar tratados e compromissos; (3) Os povos são iguais e são partes em acordos que os

\footnotetext{
${ }^{5}$ Ver a definição de pluralismo razoável in Political Liberalism. New York: Columbia University Press, 1993, p. 36.

${ }^{6}$ Ver in A Theory of Justice (1971), capítulo II, p. 54. Neste capítulo Rawls discute os princípios de justiça para uma sociedade bem-ordenada.
} 
obrigam; (4) Os povos sujeitam-se ao dever de não-intervenção; (5) Os povos têm o direito de autodefesa, mas nenhum direito de instigar a guerra por outras razões que não a autodefesa; (6) Os povos devem honrar os direitos humanos; (7) Os povos devem observar certas restrições especificadas na conduta da guerra e, (8) Os povos têm o dever de assistir a outros povos vivendo sob condições desfavoráveis que os impeçam de ter um regime político e social justo ou decente (RAWLS, 2004, p. p. 47-48). Apesar de entender que esta formulação dos princípios deixa margem para muitas discussões, Rawls pensa que este é um bom começo para lançar uma carta básica do Direito dos Povos.

Rawls extrai esses princípios da própria história e dos usos do Direito e práticas internacionais. Os representantes de povos bem-ordenados refletem sobre as vantagens desses princípios de igualdade entre povos e não veem razões para abandoná-los. São princípios que satisfazem o critério de reciprocidade válido em ambos os níveis, tanto entre cidadãos como entre povos com outros povos. Para muitos, considerada uma utopia, a realização de uma Sociedade dos Povos passa a ser para Rawls, uma utopia realista. Em um breve olhar sobre a História constatamos que este é um desejo que vem de longo prazo. Antigas epopeias, tais como a Ilíada, a Canção dos Nibelungos ou a Mahabarata, veem-se indícios de compromissos interestatais refletirem o respectivo direito tribal (inclusive costumes e código de honra) nas relações com o mundo exterior (HÖFFE, 2005, p. 267). Concordando com Rawls, pensamos que uma Sociedade dos Povos ou uma República Mundial, pode sim, ser desejada. Dado o contexto atual de globalização e complexidade tecnológica por que passa a humanidade, podemos intuir que uma Sociedade dos Povos não é somente uma questão econômica ou de Direito. É isto sim, uma imposição moral para que fronteiras nacionais possam ser suprimidas gerando condições para uma maior justiça como equidade entre os povos.

\title{
THE ORIGINAL POSITION OF JOHN RAWLS AS A MODEL FOR PEOPLES' SOCIETY
}

\begin{abstract}
This study intends to reflect on whether it would be possible to achieve the utopia proposed by John Rawls in his work The Right of the People (2001). It's a task of political philosophy, as Rawls' own admission of fulfilling a role of being realistically utopian, having the desire of expanding the limits of practicable politics possibility. His hope was a humanity based on the belief that the nature of the social world allows reasonably just constitutional democratic societies, and that the same ones were part of the Society of Peoples. In this social world, peace and justice would be obtained among liberal peoples, domestically as well as internationally. If in A Theory of Justice (1971) and in Political Liberalism (1993) Rawls
\end{abstract}


reflects on the possibility of the existence of a liberal, just and egalitarian society, in The Right of the People his reflection is on a possible global society of liberal peoples. "The great evils" of human history, such as unjust war, oppression, religious persecution, starvation, poverty, immigration, refugees and liberty of conscience propelled Rawls to write this work. The article is based on the idea of the original position as a model for constructing liberal societies. Using the allegory of the original position, which follows a few steps, as for example, the veil of ignorance, we want to demonstrate that it is possible a kind of second original position. If in the first model it serves to construct a just society in the countryside of a State, in the second model, could it serve to construct a Society of Peoples? This is the answer we intend to issue from this research.

Keywords: Law, Justice, Original Position, Rawls, Society of peoples.

\section{Referências:}

CÍCERO. Da República. São Paulo: Edipro, 1995.

BAUMAN, Zygmunt. Tempos Líquidos. Rio de Janeiro: Jorge Zahar Editora, 2007.

KANT, Immanuel. À paz perpétua. Porto Alegre: L\&PM Editores, 2008.

HABERMAS, Jürgen. The Postnational Constellation: Political Essays. Editora: JOHN WILEY PROFESSIO. USA.

HÖFFE, Otfried. A Democracia no mundo de Hoje. São Paulo: Martins Fontes, 2005.

RAWLS, John. A Study in the Grounds of Ethical Knowledge: Considered with Reference to Judgments of the Moral Worth of Character. Submitted to the Department of Philosophy, Princeton University, Feb. 1, 1950.

A Theory of Justice. Cambridge: Harvard University Press, 1971.

Uma teoria da justiça. São Paulo: Martins Fontes, 2002 a.

Political Liberalism. New York: Columbia University Press, 1993.

Collected Papers, ed. Samuel Freeman. Cambridge. MA: Harvard University Press, 1999.

Lectures on the History of Moral Philosophy. Cambridge. MA: Harvard University Press, 2000.

O liberalismo político. São Paulo: Martins Fontes, 2011.

Outline of a decision procedure of ethics. Philosophical Review, 60, p. 177-197. 1951

a.

Justiça e democracia. São Paulo: Martins Fontes, 2002 b.

Justice as Fairness: A Restatement, ed. Erin Kelly. Cambridge, MA: Harvard

University Press. Third printing, 2003.

O direito dos povos. São Paulo: Martins Fontes, 2004.

Historia da filosofia moral. São Paulo: Martins Fontes, 2005.

Barbarói, Santa Cruz do Sul, Edição Especial n.47, p.<238-250>,jan./jun. 2016 
Teoria de la justicia. Madrid: Fondo de Cultura Econômica, 1978.

The Independence of moral theory. Proceedings and Addresses of the American Philosophical Association, 48, 5-22, 1975.

The Law of Peoples. Cambridge. MA: Harvard University Press, 2001.

VOICE, Paul. Rawls Explained: From Fairness to Utopia. Chicago: Open Court, 2011.

\section{Sobre o autor:}

Ubiratan Trindade é Doutorando em Filosofia pela Unisinos. Endereço Eletrônico: trindadeumi@gmail.com 